Article

\title{
Numeric Study on the Influence of Sluice-Gate Operation on Salinity, Nutrients and Organisms in the Jiaojiang River Estuary, China
}

\author{
Xi Weng, Cuiling Jiang *, Manxue Zhang, Menglin Yuan and Tianshan Zeng \\ College of Hydrology and Water Resources, Hohai University, Nanjing 210098, China; \\ 180801010004@hhu.edu.cn (X.W.); zhangmanxuehhu@163.com (M.Z.); yml@hhu.edu.cn (M.Y.); \\ zengts0528@hhu.edu.cn (T.Z.) \\ * Correspondence: jiangcuiling@hhu.edu.cn
}

Received: 13 May 2020; Accepted: 10 July 2020; Published: 16 July 2020

\begin{abstract}
The estuary-located in the joint zone between river and ocean - has created unique ecosystems and rich biodiversity due to its complex habitat conditions. As the critical period for the growth and reproduction of estuarine organisms, the flood season is also crucial for estuary sluice to play a role in flood control and drainage. This study aims at proposing an ecological scheduling scheme that comprehensively considers the adverse factors brought by draining of the estuarine sluice to maintain different ecological functions of the Jiaojiang River estuary. A two-dimensional mathematical model in MIKE 21 was used to ascertain the change of salinity and nutrients in the study area, and results were analyzed to understand the impact of draining on estuarine organisms. Based on an analysis of the change and redistribution of salinity and nutrients, the sea area could be divided into three parts during the operation of the estuarine sluice: nearshore area with low-salt and high eutrophication, medium mixed salinity under nitrogen limitation area and high-salt under phosphorus limitation area. The aquaculture area was alternately situated in the mesohaline $(>5.0 \%$ o $-18.0 \%$ o $)$ and polyhaline $(>18.0 \%$ o) zones. The after-effects of salinity change-including the lowest value and the sharp change of salinity, especially the sharp change of salinity $(11.8 \%$ o- $12 \%$ o ) caused by large-volume discharge-would affect the growth of organisms to a certain extent, but would not be lethal. Moreover, a high-incidence red tide area was determined to be formed within 8-14 km away from the estuarine sluice after the sluice opening, and the area of this zone was firmly related to the opening schemes. The study suggested that the proposed sluice should choose the mode of draining frequent with the small flow at neap tide in order to reduce the stress of sluice construction and operation on mariculture organisms and phytoplankton in Jiaojiang River estuary on the strength of the ecological restoration measures for estuary and riparian zones.
\end{abstract}

Keywords: hydrodynamics; estuary sluice; spatial distribution; salinity; nutrient; organism; twodimensional model

\section{Introduction}

Estuaries, located at the confluence of rivers and oceans, are the main channel of material between basin and marine, and also one of the natural habitats of many aquatic organisms [1]. Due to the particular location and the interaction between land and sea, the estuarine ecosystem has unique environmental characteristics such as the mixing of freshwater and saltwater and nutrients enrichment, as well as critical ecological services functions such as biodiversity maintenance [2-4]. Estuarine sluice construction has positive benefits such as flood prevention, increasing freshwater resources and improving the urban water landscape [5]. However, it also directly isolates the interaction between rivers and oceans, disrupts the circulation of freshwater and nutrients into the marine system [6] and changes the seasonal fluctuation 
of salinity and nutrients in the coastal waters [7]. Hence, the construction of sluices in estuaries can not only significantly disrupt hydrodynamic processes, but also change the freshwater input and nutrients distribution to a certain extent, and as a result, habitat functions. Specifically, salinity, as a sensitive ecological factor in estuarine habitats, is related to the distribution of phytoplankton [8], while the concentration and distribution pattern of nutrients restrict the biomass of phytoplankton [9]. Besides, there is established consensus that the increase of nutrients is the leading cause of water eutrophication, which has been identified as one of the greatest threats to the health of coastal ecosystems [10]. There is ample evidence that maintaining a suitable salinity and nutrient environment is a fundamental guarantee of the survival and reproduction of organisms and the maintenance of biodiversity [11-13]. However, the presence of sluices will change the distribution and structure of organisms in estuaries [14], thus affecting the structure and function of the entire marine ecosystem $[15,16]$.

At present, the researches on the impact of sluice construction on the ecological environment mainly focus on the change of water environment after sluice construction, the evolution trend of brackish water and saltwater biome, the impact of the changing freshwater input flow in the estuary on the ecosystem [17-19] and the ecological water demand of different estuaries and the evaluation method of ecological health system, etc. [20,21]. However, there is a lack of study on the changes of salinity and nutrients caused by the operation of estuarine sluice, as well as the influence factors on organisms. In recent years, Jiaojiang River estuary is planning to build an estuarine sluice. Nevertheless, the water quality of Jiaojiang estuary is affected by the coastal sanitary sewage, aquaculture wastewater discharge and the loss of agricultural fertilizer, which result in a severe pollution of dissolved inorganic nitrogen and active phosphate. Jiaojiang River sea area is a high-incidence area of red tide outbreak in China's coastal areas, which not only threatens the biodiversity and stability, but also harms tourism and aquaculture [22]. Therefore, it is of considerable significance to reasonably evaluate the stress of sluice construction on the estuarine ecosystem and to develop appropriate sluice regulation measures for the protection of the estuarine ecosystem.

The impact of sluice construction on the water ecological environment was mainly studied by establishing a mathematical model to simulate the hydrodynamic processes and the change of salinity and nutrients [23]. Since the flow structure and nutrient distribution characteristics of natural rivers are relatively complex, to accurately reflect the influence of sluice construction, a plane two-dimensional turbulent flow model is generally used to simulate the flow field distribution. As computer performance greatly improved and mathematical model simulation technology developed, many scholars have used the two-dimensional numeric simulation method to simulate the different characteristics of estuaries and obtained satisfactory results. For example, Le Thi Viet Hoa et al. [24] used the numeric model to analyze the comprehensive impact of dams on the Mekong River and sea level rise on the hydrodynamic environment of the Mekong river estuary. At present, there are many two-dimensional models widely used in the world, among which MIKE 21, a useful and powerful tool based on two-dimensional free surface flow simulation for simulating hydrodynamics and environment, is widely used in the shallow estuary region [25-27]. This study demonstrated the practicality of the MIKE 21 model in hydrodynamic simulation and reflection of nutrient distribution and movement in the estuarine system.

In this study, different scheduling schemes of estuarine sluice were designed, and the salinity field and nutrient concentration of estuarine and coastal waters under each scenario were simulated and calculated by the mathematical model. Subsequently, from the perspective of giving full play to the economic benefits of the project and relieving the adverse effects, the specific environmental regulation measures to reduce estuarine stress were proposed. (Determine the discharge volume, discharge time, duration, and so on.)

\section{Study Area: Jiaojiang Catchment}

Jiao (ling) jiang River basin, located in the central coastal area of Zhejiang, China, is triangular and between the latitudes $28^{\circ} 22^{\prime}-29^{\circ} 19^{\prime} \mathrm{N}$ and longitudes $120^{\circ} 14^{\prime}-121^{\circ} 55^{\prime} \mathrm{E}$. Jiao (ling) jiang River system is the largest water system in Taizhou City and the third-largest water system in Zhejiang 
Province. The lower reaches of Jiaojiang River is a tidal river, and mainly affected by the estuary. Jiaojiang River estuary is a strong tidal estuary and the tide type is irregular semidiurnal tide [28]. The Taizhou Bay outside the estuary shapes like a trumpet, which is a typical regular semidiurnal tide. In 2010, a large-scale reclamation project was completed on the south bank of Jiaojiang River estuary, and pond mariculture has become one of the primary aquaculture mode [29] (Figure 1).

In 2013, 13 vertical lines were set up to sample the water body of Jiao (ling) jiang River (Figure 1), among which five (1\#-5\#) were set up in the mainstream and eight (6\#-13\#) were set up in the estuary and the coastal waters. Water samples were taken at the characteristic moments of maximum flood tide, high slack water, maximum ebb tide and low slack water of the first half tide of 13 vertical lines in the flood season of large, medium and small tide flood voyages. The monitoring contents included flow rate, salinity $(\mathrm{S})$, dissolved inorganic nitrogen $\left(\mathrm{DIN}=\mathrm{NO}_{3}^{-}+\mathrm{NO}_{2}^{-}+\mathrm{NH}_{4}^{+}\right)$and o-phosphate $\left(\mathrm{PO}_{4}^{-}\right)$and the monitoring frequency was once per month.

The distribution and variation of salinity in Jiao (ling) jiang River Basin in rivers, estuaries, and offshore were related to the influence of many factors such as tidal current and runoff. The average salinity of Lingjiang River channel, Jiaojiang river channel and Jiaojiang River estuary and its periphery was $0.4-8.3 \%$ o, $11.1-18.0 \%$ o and $19.9 \%$ o- $28.6 \%$, respectively. On the whole, the salinity increased gradually from the upper Lingjiang river channel to the lower Jiaojiang River channel, then to Jiaojiang River estuary and periphery.

Monitoring results showed that the DIN concentration ranged from 1.34 to $2.40 \mathrm{mg} / \mathrm{L}$, and $o$-phosphate concentration ranged from 0.20 to $0.40 \mathrm{mg} / \mathrm{L}$ in Jiaojiang River while in the estuary and nearshore waters the range was $0.61-0.89 \mathrm{mg} / \mathrm{L}$ and $0.032-0.042 \mathrm{mg} / \mathrm{L}$. The nutrient concentration in the mainstream of Jiaojiang river was significantly higher than that in the estuary and nearshore waters.

According to statistics, there were 58 genera (species) of phytoplankton in the Jiaojiang River estuary area, which belong to five phyla. Bacillariophyta was the main dominant phylum, accounting for $76 \%$ of the total species, followed by Pyrrophyta and Chlorophyta.

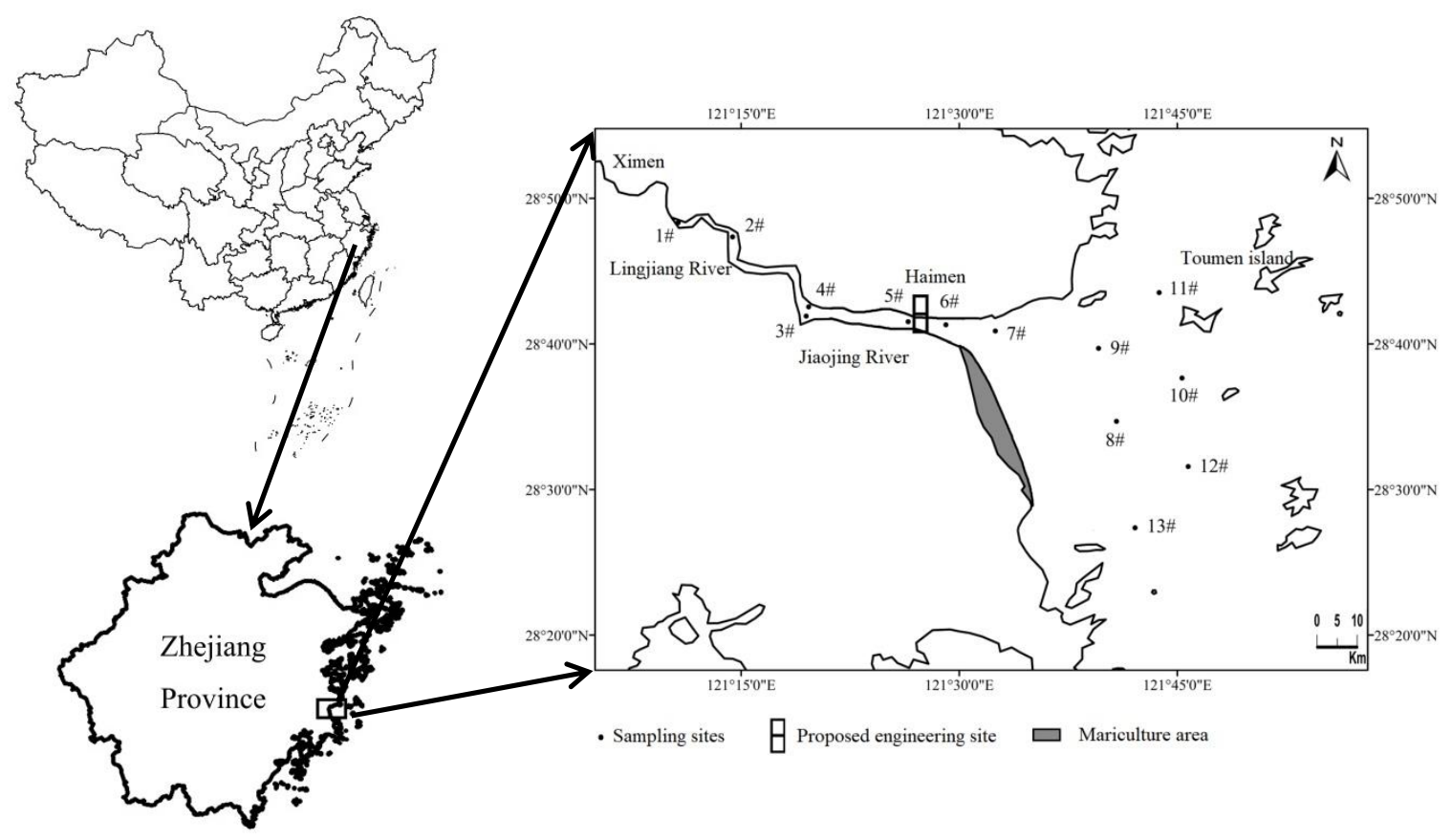

Figure 1. Sampling points proposed estuarine sluice site and aquaculture area location in the study area.

In order to fully reflect the impact of the sluice construction on salinity and nutrients of the estuary and coastal waters, the proposed site of the sluice was selected at Niutoujing after considering the current topography, water quality, policies and other factors (Figure 1). The proposed site is two kilometers 
upstream of the second Jiaojiang Bridge in the Niutoujing operation area of Haimen port area, Taizhou port. Xiaoyuanshan is on the left bank, Niutoujing is on the right bank, and the river width is about $900 \mathrm{~m}$. According to the terrain conditions, from left to right, the following are arranged in sequence: diversion dam at the left bank, tidal sluice, diversion dam at the right bank, double-lane ship lock and dam blocking at the right bank. The tidal sluice has a total of 24 drain holes, each with a net width of $25 \mathrm{~m}$ and a total net width of $600 \mathrm{~m}$, and the elevation of sluice bottom is $-5.0 \mathrm{~m}$. The designed normal pool level and the lowest water level at upstream of the sluice gate are $2.6 \mathrm{~m}$ and $1.5 \mathrm{~m}$, respectively. In addition, to facilitate the passage of migratory fish, fishways are set up on the diversion dams on both river banks.

\section{Model Simulation}

Keeping the objective of the study in view, two modules of the MIKE 21 FM software (Danish Hydraulic Institute (DHI)_Water, Environment and Health, Denmark) were used in this study [26]. The flow regime was calculated by setting up the hydrodynamic (HD) module followed by the transfer and diffusion process of salinity, DIN and $o$-phosphate by the transmission (TM) module.

\subsection{Model Domain and Bathymetry}

The two-dimensional hydrodynamic model was verified from Ximen station to Toumen island station and simulated from Haimen station (sluice site) to Toumen island station according to the sluice site scheme and the location of hydrologic synchronous observation stations. The tributaries were simplified within both ranges. The unstructured Flexible Mesh (FM) triangular grid was used for model calibration and calculation [30], where the area of a single triangular grid was controlled within $8000 \mathrm{~m}^{2}$. The topographic data of the channels in the Yongjiang River basin (measurement scale: 1:5000) and outside the Yongjiang estuary (measurement scale: 1:5000) were obtained from the topographic survey results in 2013 by Zhejiang Hohai Surveying and Mapping Institute, China. The adjacent point method was used to interpolate the grid to form the calibration (Figure 2) and calculation (Figure 3) mesh grids of hydrodynamic module.

\subsection{Model Calibration}

The boundary conditions of the hydrodynamic validation model were based on the hourly tide level data of Ximen station and Toumen Island Station from 14 to 16 June 2014, with an interval of one hour. Through model debugging and running, the measured and simulated values of tidal-level time series are presented in Figure 4 and the specific value of main parameters are presented in Table 1. It provides an excellent visual comparison of the prediction and observation of the model, and the numeric fitting of the two stations is proper, indicating that the model can be used for subsequent simulation calculation.

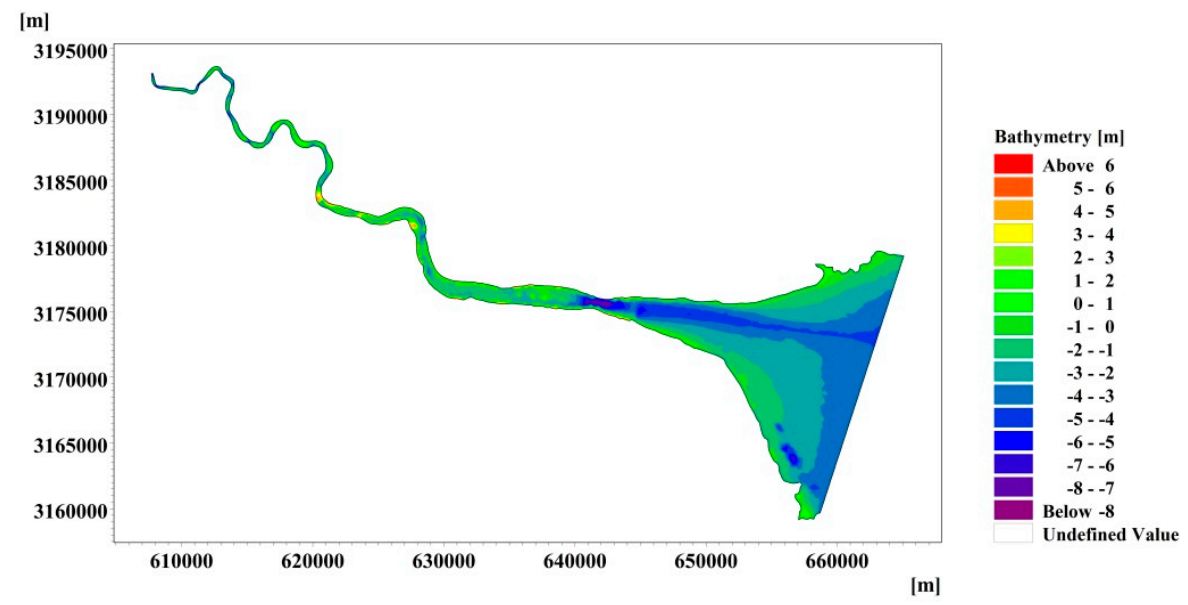

Figure 2. Bathymetry of the calibration area. 


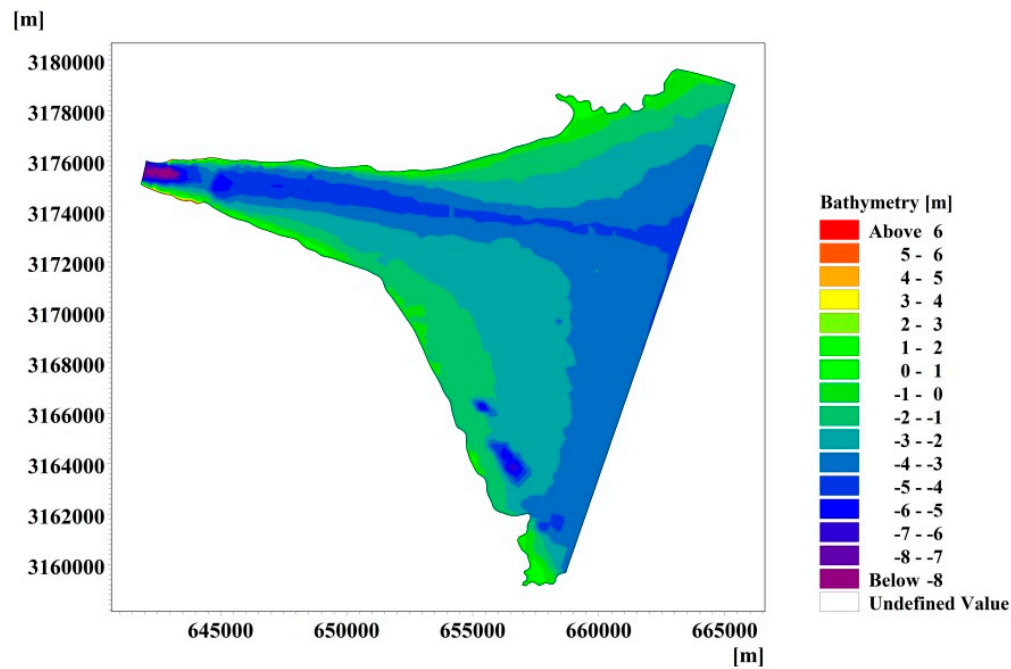

Figure 3. Bathymetry of the calculation area.

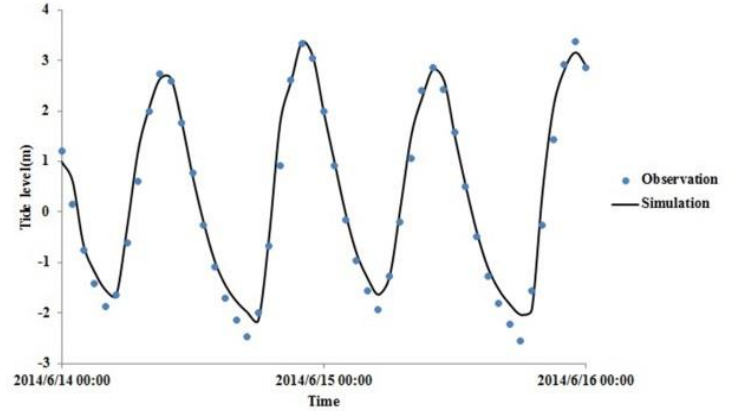

(a)

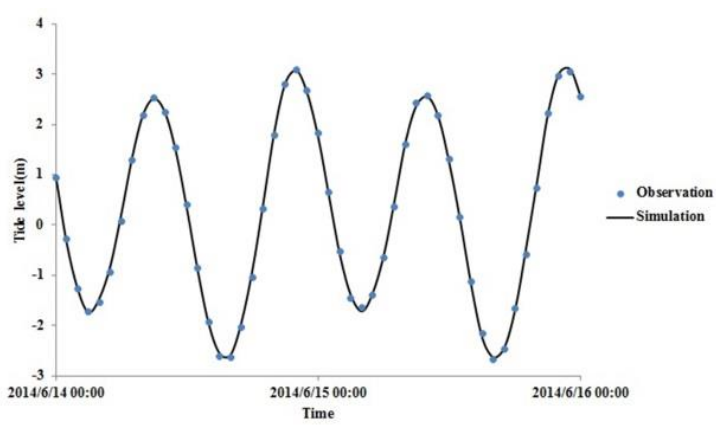

(b)

Figure 4. Hydrodynamic (HD) model calibration: comparison between model simulated and measured tidal level. (a) Haimen; (b) Langjishan.

Table 1. Details of the variables used as inputs in HD module.

\begin{tabular}{cc}
\hline Parameter & Value Used \\
\hline Manning's number (i.e., 1/Manning's coefficient) & $90 \mathrm{~m}^{1 / 3} / \mathrm{s}^{*}$ \\
Smagorinsky coefficient-Eddy viscosity formulation & 0.28 \\
Dry and flood & $\mathrm{h}_{\mathrm{dry}}=0.005 \mathrm{~m}$ \\
& $\mathrm{~h}_{\text {flood }}=0.005 \mathrm{~m}$ \\
& $\mathrm{~h}_{\text {wet }}=0.005 \mathrm{~m}$
\end{tabular}

* The value of Manning's number recommended in the MIKE operation manual is between 30 and 50 , which is mostly for the sandy river. Jiao (ling) jiang River is a tide influence river, where fine-grained sediment will appear, and the bottom friction resistance is small. Under the MIKE frame, the Manning's number is recommended to be between 70 and 100 .

After the completion of the hydrodynamic model calibration, the transmission model was calibrated. The validation results are presented in Figure 5. The simulation results are in good agreement with the measured data, and the model accuracy can meet the prediction requirements.

\subsection{Model Setup}

For the present study, the hydrologic upper and lower boundary conditions were, respectively the estuarine sluice control boundary (Figures 5 and 6 ) and the measured tidal level every $1 \mathrm{~h}$ during the spring tide and neap tide of Toumen Island Station in June 2013. 


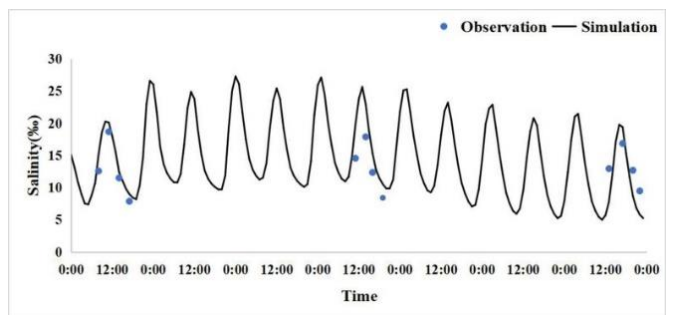

(a)

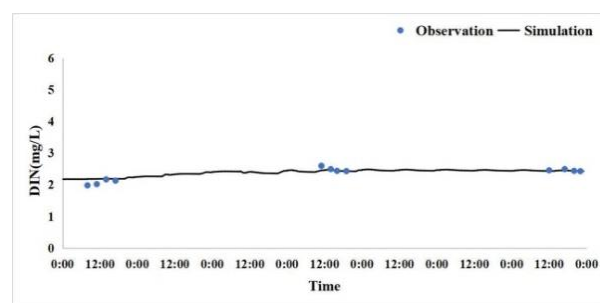

(b)

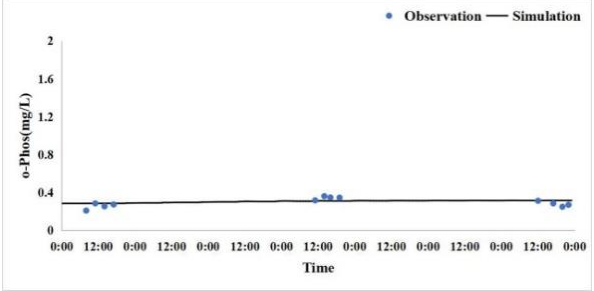

(c)

Figure 5. Transmission (TM) model calibration: comparison between model simulated and measured values of each index in Haimen station. (a) Salinity; (b) DIN; (c) o-phosphate.

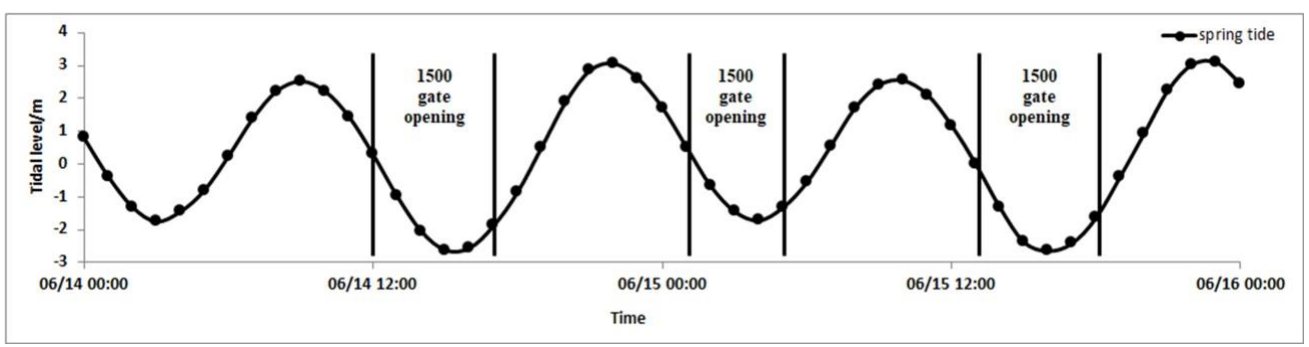

(a)

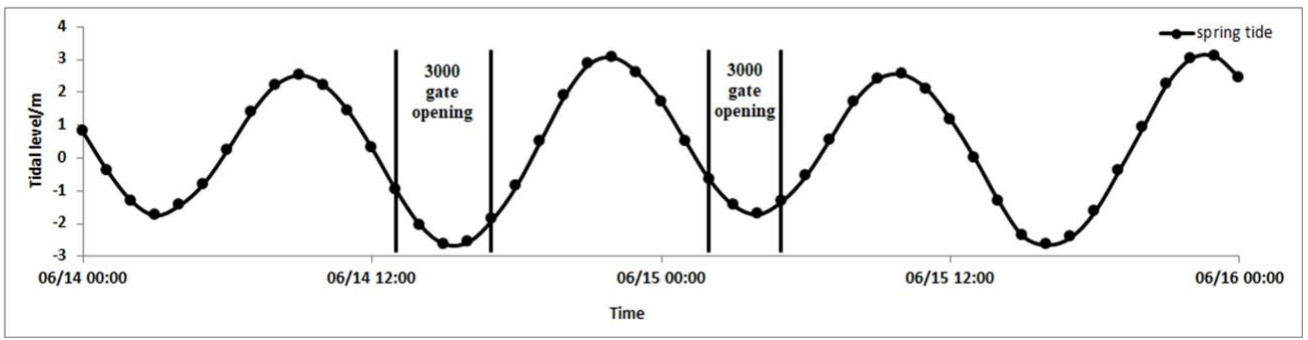

(b)

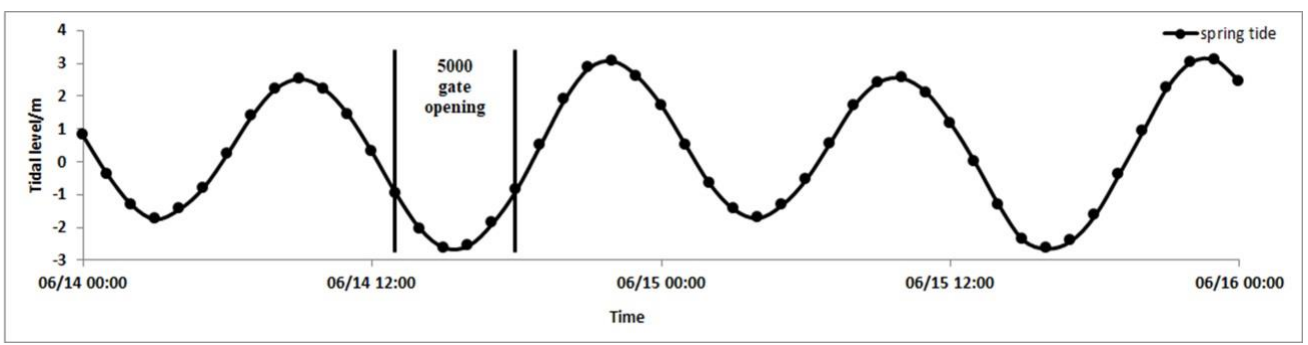

(c)

Figure 6. Dispatch diagram of gate control boundary discharging with flow of (a) $1500 \mathrm{~m}^{3} / \mathrm{s}$, (b) $3000 \mathrm{~m}^{3} / \mathrm{s}$ and (c) $5000 \mathrm{~m}^{3} / \mathrm{s}$, respectively during spring tide. 
In the design of the operational schemes of the sluice, the opening time and discharge flow of estuarine sluice were mainly considered. The opening time was selected at spring tide and neap tide. The discharge flow was set as the designed opening flow in the flood season of typical high flow year with a frequency of $0.1 \%, 5 \%$ and $40 \%$, which were, respectively $5000 \mathrm{~m}^{3} / \mathrm{s}, 3000 \mathrm{~m}^{3} / \mathrm{s}$ and $1500 \mathrm{~m}^{3} / \mathrm{s}$. During the operation of the estuarine sluice, the way of blocking the water at the rising tide and releasing the water at the falling tide was adopted to block the upstream of the high tide level under the estuarine sluice and ensure the timely discharge of the flood. At the same time, the closing time of the estuarine sluice was set at 60 min to ensure the function of blocking the tide of the estuarine sluice and avoid the generation of concussion wave. According to the tide level conditions of the lower boundary, the specific opening time of six sluice scheduling schemes is presented in Figures 6 and 7.

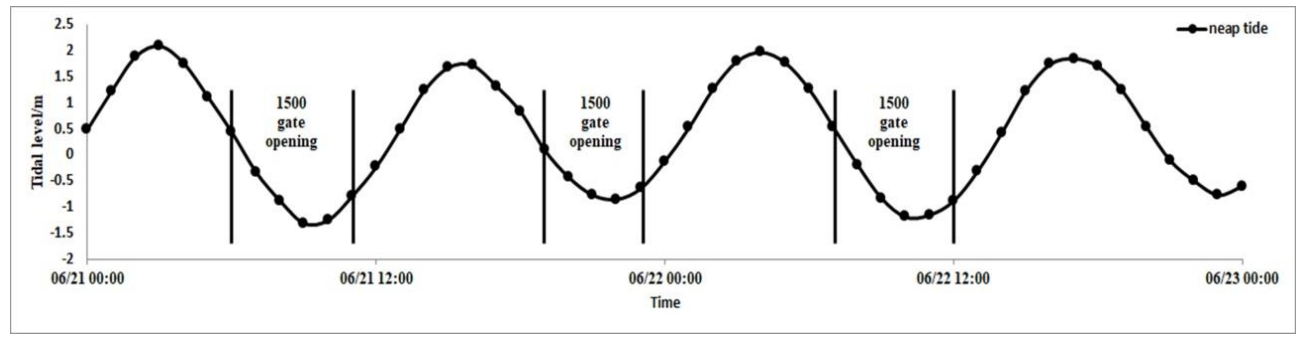

(a)

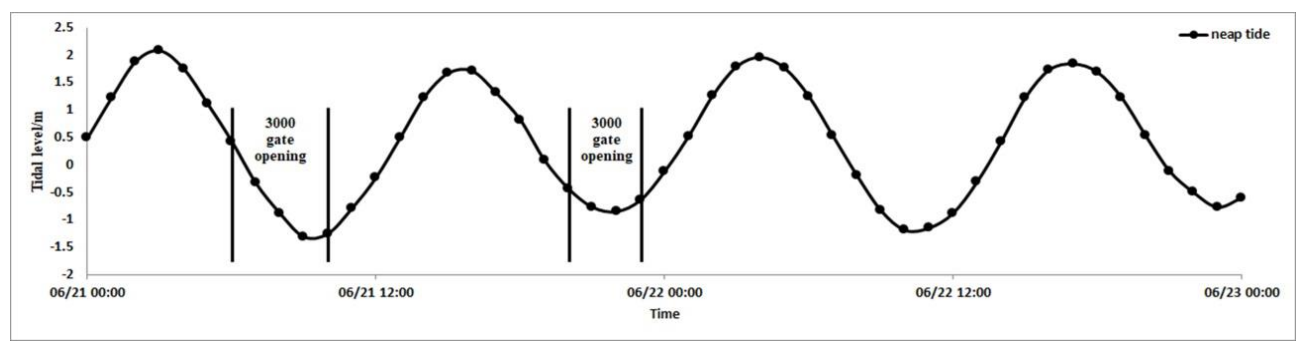

(b)

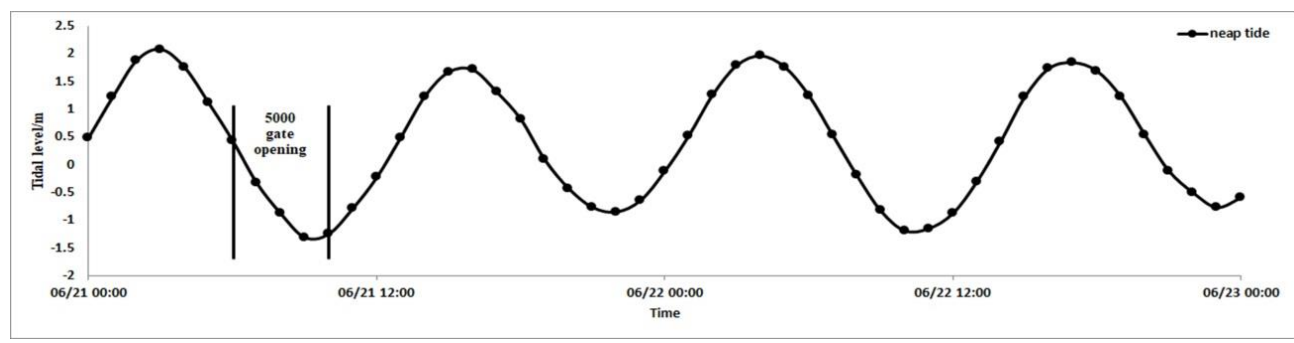

(c)

Figure 7. The dispatch diagram of gate control boundary discharging with flow of (a) $1500 \mathrm{~m}^{3} / \mathrm{s}$, (b) $3000 \mathrm{~m}^{3} / \mathrm{s}$ and (c) $5000 \mathrm{~m}^{3} / \mathrm{s}$, respectively during spring tide.

In the TM model, the background concentration values of salinity, TIN and $o$-phosphate were obtained by interpolation of the average values of water quality monitoring. The lower boundary conditions of salinity, TIN and $o$-phosphate were set as the value of Toumen Island Station, and the upper boundary conditions of TIN and $o$-phosphate were set as the current concentration of Haimen. For the lack of salinity information on the upstream water body after the sluice construction of Jiaojiang estuarine sluice, a detailed analysis using a pairwise comparison of salinity value was made between the upper water body before and after the construction of the nearby Jiangxia drainage project in Wenling, Ningbo. The monitoring data in 2005 after construction was $1.67 \%$, which was only $0.24-0.10$ times of the salinity before construction in 1985 . The results demonstrate a sharp fall in the salinity value of the 
drainage outlet after the construction of the drainage project. Therefore, the value of salinity of the upper boundary condition was considered as $0.398 \%$ of the minimum salinity of Lingjiang River.

\section{Model Output Result and Discussion}

In this section, the changes of salinity, nutrients, and flow velocity after the opening of sluice are analyzed, and thus determine the pressure brought by sluice operation on aquaculture organisms and phytoplankton.

\subsection{Salinity}

After the construction of tidal sluice on Jiaojiang estuary, a similar cecum channel would be formed to connect with the sea. The estuarine sluice should begin to drain at the early stage of ebb tides, as the tidal level of the outer sea decreased continuously. Subsequently, the salinity value of the area near the sluice decreased rapidly, causing a drastic change of the salinity field, whist the change of the salinity value of the nearshore area was not significant. During modeling, the salinity value generally showed a decreasing process from Jiaojiang estuary (7\# vertical line), through the middle part of the bay (8\# and 9\# vertical line) and to the periphery (10\#, 11\#, 12\#, 13\# vertical line). Such change, where a joint influence is involved, results from the trumpet-shaped opening of Taizhou Bay and the limited amount of freshwater and the salinity compensation of the outer sea during the high tide.

The tidal currents in this sea area are regular semidiurnal tides showing a reciprocating flow and the salinity value also fluctuates with it. During ebb tide, the contour line of salinity extended outward in the shape of the tongue with more significant curvature. During high tide, the contour line extended to the interior of estuary in the form of an arc with a smaller curvature. There is no doubt that the salinity value would drop to the lowest at low tide and the impact area caused by the discharge of freshwater would be the largest. Hence, the study area could be further differentiated by the salinity value. Salinity data at three times of low tide during the simulation were grouped by salinity regimes of tidal fresh $(<0.5 \%$ o), oligohaline $(>0.5-5.0 \%)$, mesohaline $(>5.0-18.0 \%$ o $)$ and polyhaline $(>18.0 \%$ o) [31]. The drawing results are presented in Figure 8.

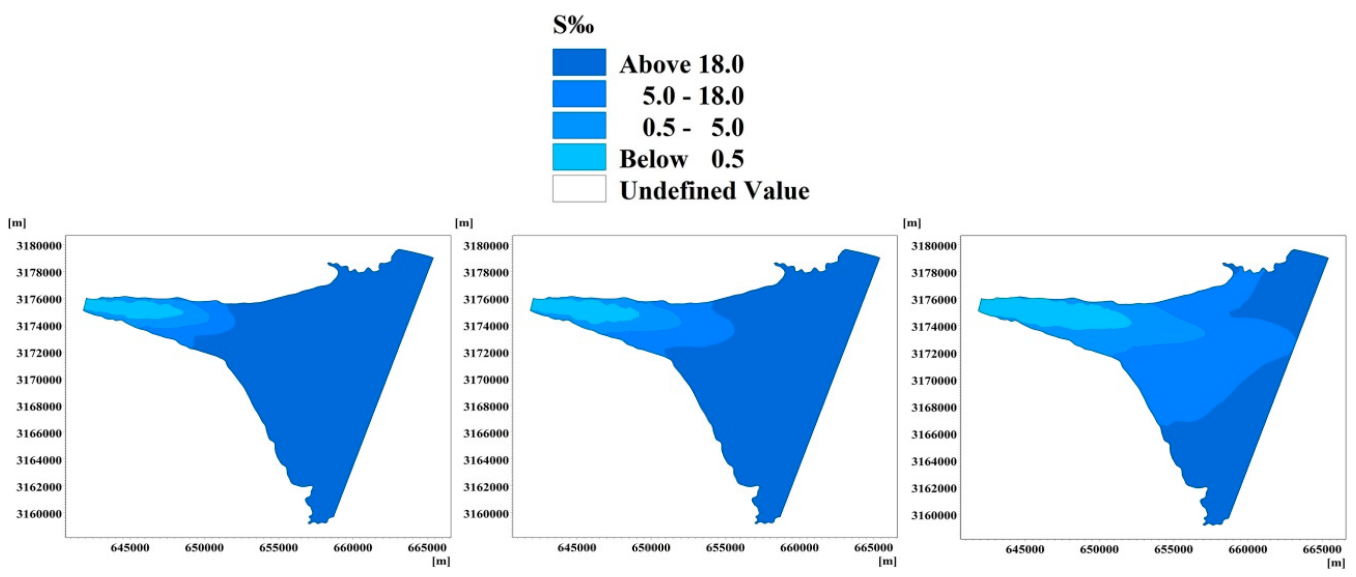

(a)
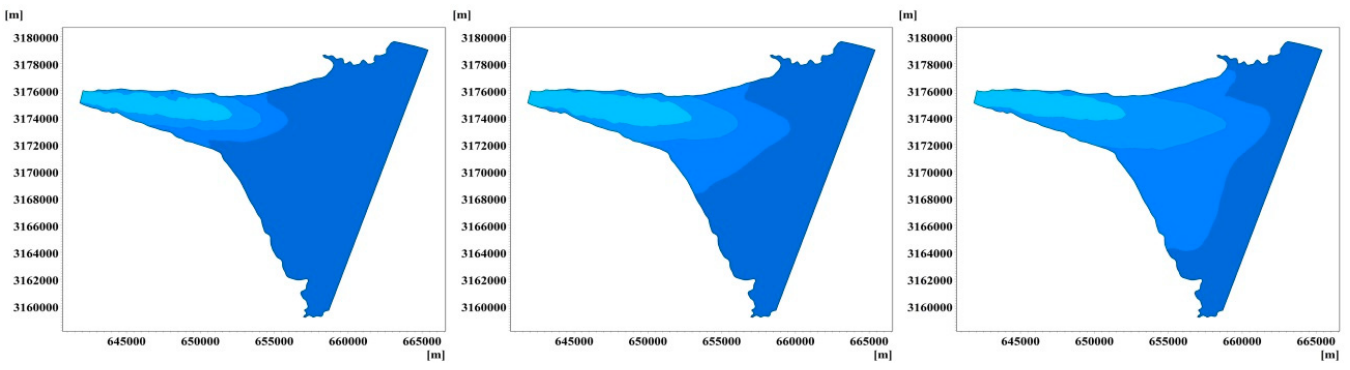

(b)

Figure 8. Cont. 

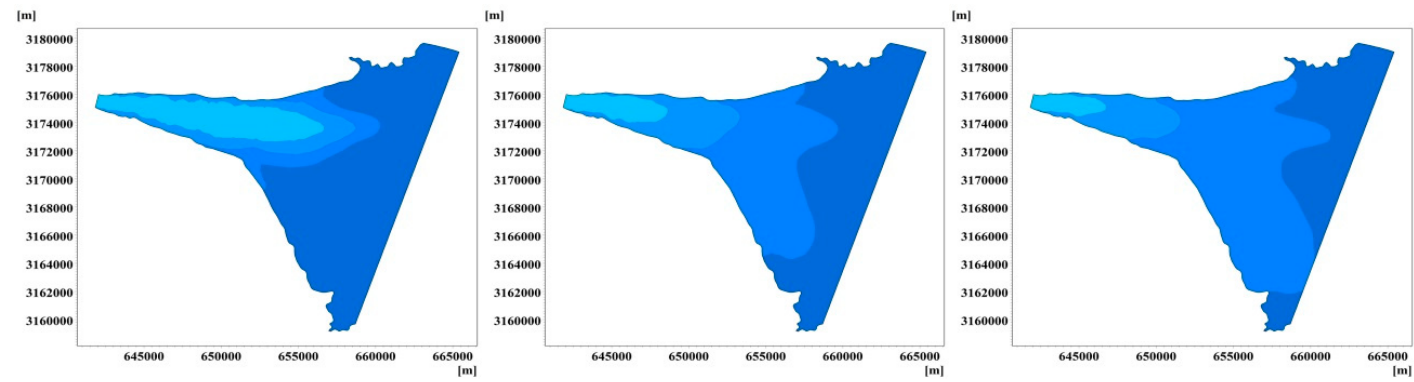

(c)
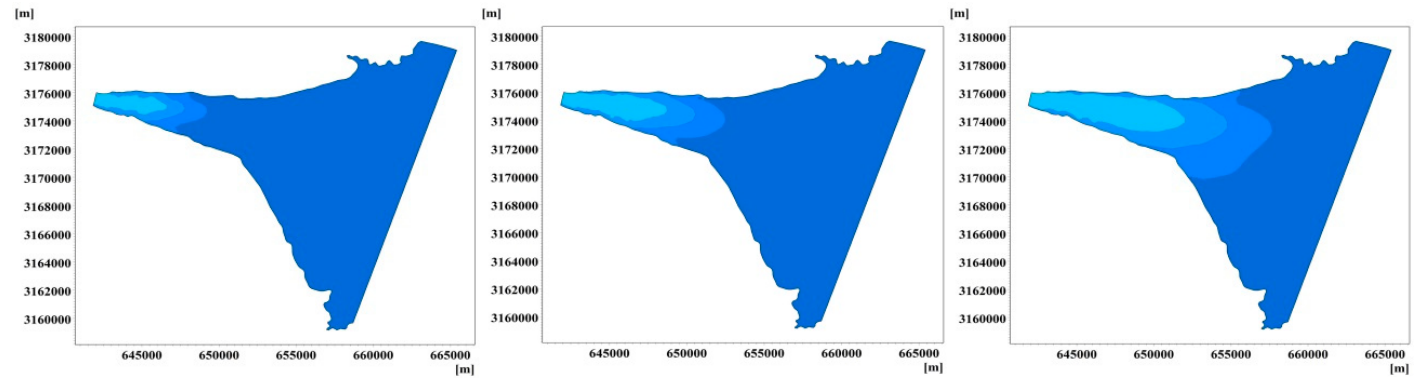

(d)
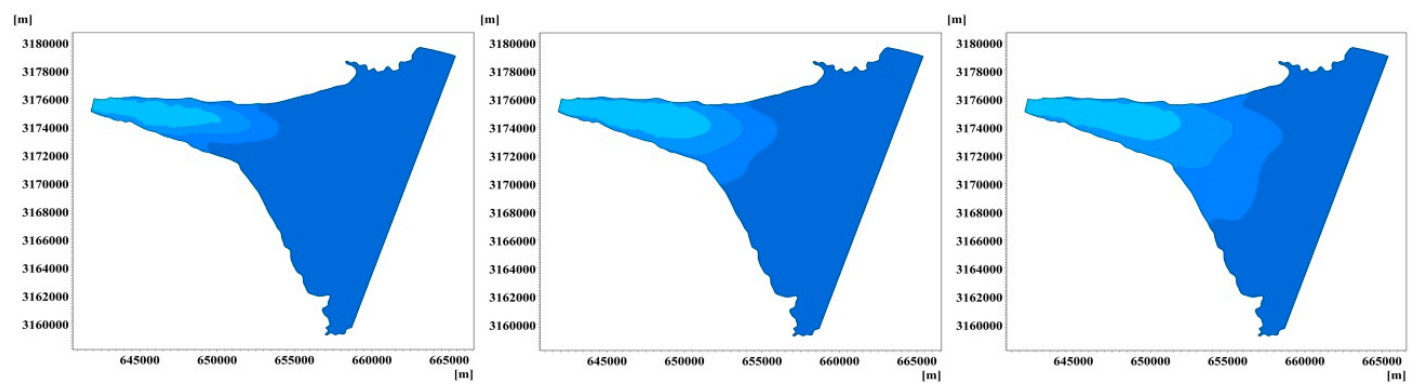

(e)
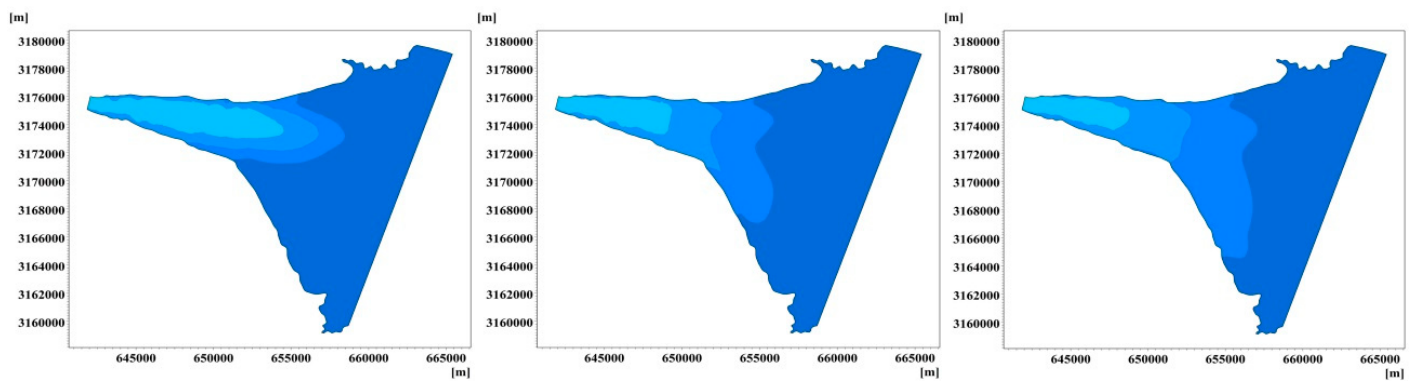

(f)

Figure 8. Distribution diagram of salinity sluice at three times of low tide after the opening of estuarine sluice. (a) Discharged with flow of $1500 \mathrm{~m}^{3} / \mathrm{s}$ during spring tide; (b) discharged with flow of $3000 \mathrm{~m}^{3} / \mathrm{s}$ during spring tide; (c) discharged with flow of $5000 \mathrm{~m}^{3} / \mathrm{s}$ during spring tide; (d) discharged with flow of $1500 \mathrm{~m}^{3} / \mathrm{s}$ during neap tide; (e) discharged with flow of $3000 \mathrm{~m}^{3} / \mathrm{s}$ during neap tide; (f) discharged with flow of $5000 \mathrm{~m}^{3} / \mathrm{s}$ during neap tide.

As shown in Figure 8, (1) The estuarine sluice would be closed after the end of the first low tide when it was discharged at a large flow of $5000 \mathrm{~m}^{3} / \mathrm{s}$. The mixing effect of tidal current made the areas of tidal fresh reduce continuously, from $12.4 \mathrm{~km}$ in front of the sluice to within $4.6 \mathrm{~km}$ (c) at spring 
tide and from $11.8 \mathrm{~km}$ to within $5.6 \mathrm{~km}$ (f) at neap tide, while the areas of mesohaline expanded continuously. Due to the difference of tidal dynamics, the extended range of mesohaline area at neap tide was smaller than that at spring tide, and it could be as far as the regional boundary (c) at spring tide; (2) The estuarine sluice would remain open at all times of low tide when it was discharged at a small flow of $1500 \mathrm{~m}^{3} / \mathrm{s}$. With the continuous replenishment of freshwater, the areas of tidal fresh expanded continuously from $5.8 \mathrm{~km}$ to $9.2 \mathrm{~km}$ (a) in front of the sluice at spring tide, and from $3.8 \mathrm{~km}$ to $8.7 \mathrm{~km}(\mathrm{~d})$ at neap tide, whose influence range even exceeded the large flow.

Moreover, the salinity fluctuation brought by water release would repeatedly cover the coastal aquaculture area on the south bank of Jiaojiang River estuary (Figure 8). According to the investigation, shellfish (clams and Sinonovacula constricta), bass, black snapper and other fish, as well as green crabs, are the primary aquaculture organisms in Zhejiang coastal areas. For all species and life stages, the lethal salinity is $5 \%$ o- $8 \%$, and the salinity amplitude should never surpass $10 \%$ or it will affect their growth. Therefore, to figure out whether the salinity change would become a major threat in the aquaculture area, the salinity values under different scheduling schemes were randomly selected and statistically calculated, and the results are shown in Figure 9. It can be seen from Figure 9 that the minimum value of the salinity field in the aquaculture area was $9 \%$ o- $15 \%$ o when water was released in each regulation scheme, which was higher than the survival limit value of $8 \%$ o of aquaculture organisms. Likewise, the fluctuation range of salinity was not higher than or substantially higher than the upper limit of $10 \%$ at spring tide and neap tide, where the range with the increase of discharge was $5.6 \%$, $9.5 \%$ ond $12 \%$, in the former and $1.8 \%$ o, $8.4 \%$ o and $11.8 \%$, in the latter. The results indicated that the low salinity drainage had little impact on the aquaculture of Jiaojiang River estuary. Moreover, the opening of the sluice with the small flow was more conducive to the growth and reproduction of aquaculture organisms in the sea area.

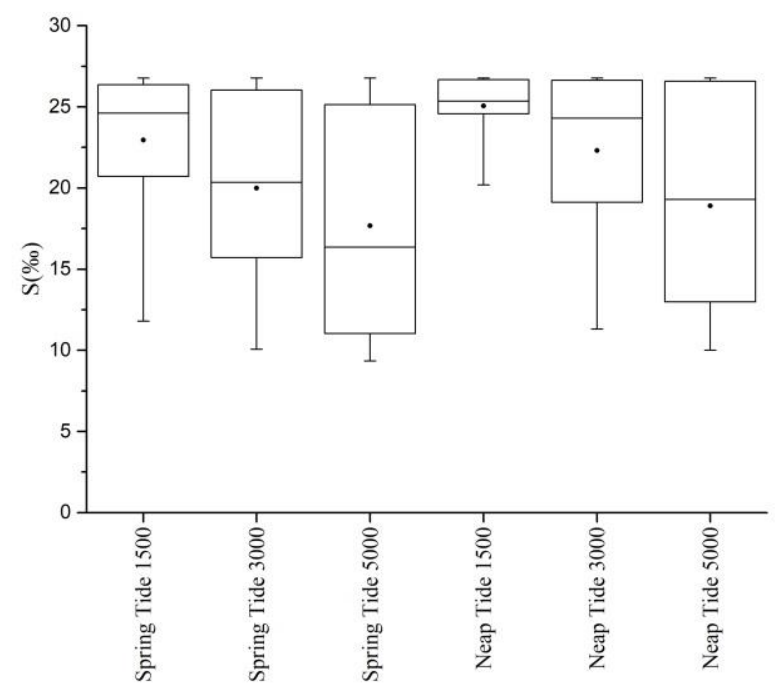

Figure 9. Salinity fluctuation in aquaculture area under different opening schemes.

\subsection{Nutrient Restriction}

The supply of nutrients plays a crucial role in the algae competition. In some sea areas, especially in semi-closed bays, due to the increase of nutrients flux into the sea, the structural distribution of nutrients changes, which have a corresponding impact on the population structure of phytoplankton [32]. The measured data showed that the nutrient concentration in the mainstream of Jiaojiang River was significantly higher than that in the estuary and coastal water. Therefore, the upper high concentration nutrient drainage of the estuarine sluice after construction would change the nutrient structure in the estuary, which would have a strong selective effect on the phytoplankton community. Michael Neill [33] proposed a method of mapping the superposition of nutrients and salts to determine the 
limiting factor of phytoplankton at any salinity. According to the drawing method, the ratio of $\mathrm{DIN}\left(=\mathrm{NO}_{3}^{-}+\mathrm{NO}_{2}^{-}+\mathrm{NH}_{4}^{+}\right)$and $o$-phosphate $\left(\mathrm{PO}_{4}^{-}\right)$on the vertical axis in the overlay chart was set as the Redfield atomic ratio that was easy to be bioavailable and satisfied for the growth of aquatic plants, i.e., $\mathrm{N}: \mathrm{P}=16: 1$ [34]. When the nutrient map was superimposed, the lowest trend line represented the limiting nutrient of algae under any salinity. The drawing results are presented in Figure 10.

The $o$-phosphate trend line in Figure 10a was located at the bottom of the superposition figure, which showed that within the sampling date, $o$-phosphate $(\mathrm{P})$ was the limiting nutrient when the salinity of the Jiaojiang River estuary was less than 30\%. The trend line of DIN and o-phosphate tended to converge with the increase of salinity, indicating that the limiting degree of $\mathrm{P}$ tended to decrease with the increase of salinity.

When the proposed estuarine sluice released water (Figure 10b-g), the concentration of DIN and o-phosphate under the sluice would increase significantly, which could deteriorate the eutrophication of the estuary. Moreover, as can be seen from the diagrams, the distribution of nutrients was similar, where the concentration near the shore was high, while that in the open sea was low. At the same time, the diagrams provided an insight of a good correlation between the concentration of nutrients and salinity, which indicated that the reduction of nutrient content was mainly affected by the dilution of outer seawater in the process of mixing. Not only that, $\mathrm{N}$ became the limiting factor in the nearshore area due to the different increase degree of $\mathrm{N}$ and $\mathrm{P}$ input. Meanwhile, in the process of transition from low salinity to high salinity, $\mathrm{P}$ changed more rapidly in the salinity gradient direction, which increased the degree of the water body in P limitation, accordingly, causing limitation in the open sea turned into P. By comparing Figure $10 \mathrm{~b}-\mathrm{g}$, it was not difficult to find that the salinity value of the transition from $\mathrm{N}$ limitation to $\mathrm{P}$ limitation in the estuarine environment increased with the discharge volume, which was the same as the influence rule of different scheduling schemes on the salinity field. Furthermore, in addition to the discharge volume, the effect of tidal dynamics was fully reflected in the difference of the transitional salinity value, in other words, the change was more obvious at spring tide.

\subsection{Effects on Phytoplankton}

In Jiaojiang River estuary and sea area, red tides of Gymnodinium (Dinophyta), Skeletonema costatum (Bacillariophyta) and Thalassiosira (Bacillariophyta) have occurred for many times. According to the survey, the first dominant phylum of phytoplankton in Jiao (Ling) River basin was Bacillariophyta, while the second dominant phylum was Chlorophyta $(27 \%)$ and Cyanophyta $(11 \%)$ in freshwater areas and Dinophyta in estuary areas. The total proportion of the first and second dominant phyla in the two regions is $93 \%$ and $95 \%$, respectively, which accounted for most the total phytoplankton species composition in the two regions. Therefore, we predicted that the community structure succession of the dominant species of phytoplankton after the construction of the sluice would happen among the first and second dominant species before the construction.

Various phytoplankton shows different adaptability to the change of flow velocity, but the one common is that tremendous flow velocity can interfere with its floating for photosynthesis. From the flow velocity diagram of each representative vertical line, the disturbance of estuarine sluice to the water body was mainly reflected in the sudden maximum value appearance of flow velocity compared with the flow velocity before water release. According to statistics, with the increase of set discharge, the maximum velocity of each vertical line was between $0.35-2.07 \mathrm{~m} / \mathrm{s}, 0.63-2.15 \mathrm{~m} / \mathrm{s}$ and $0.95-2.15 \mathrm{~m} / \mathrm{s}$, respectively at spring tide and between $0.58-1.37 \mathrm{~m} / \mathrm{s}, 0.61-1.38 \mathrm{~m} / \mathrm{s}$ and $0.82-1.38 \mathrm{~m} / \mathrm{s}$, respectively at neap tide. Compared with Dinophyta, Bacillariophyta have a more extensive range of suitable flow velocity and can survive in water bodies of $0.05-2.5 \mathrm{~m} / \mathrm{s}$. Therefore, from the perspective of flow velocity change, it is believed that Bacillariophyta can better adapt to the change of flow velocity when the sluice was in frequent stop-start motion in flood season. 


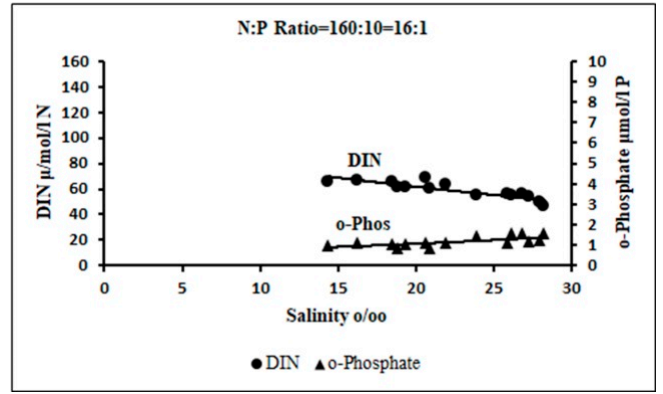

(a)

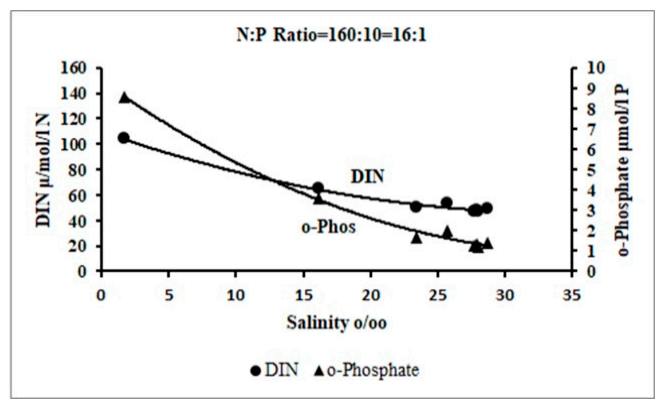

(b)

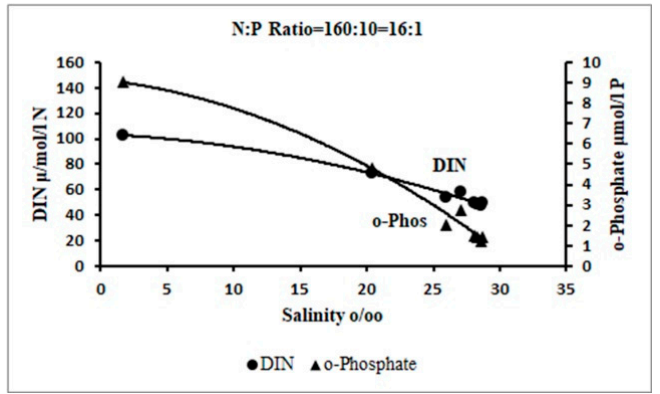

(d)

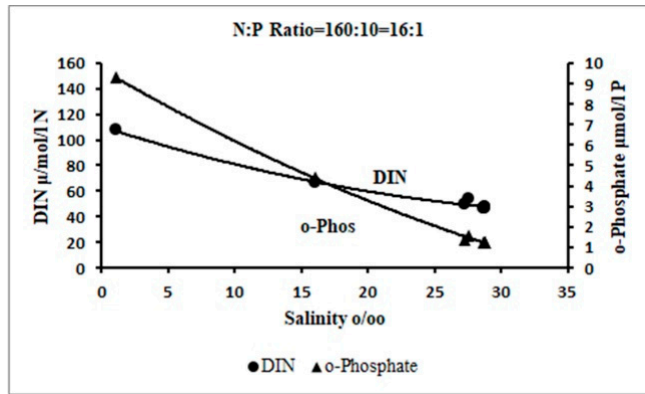

(f)

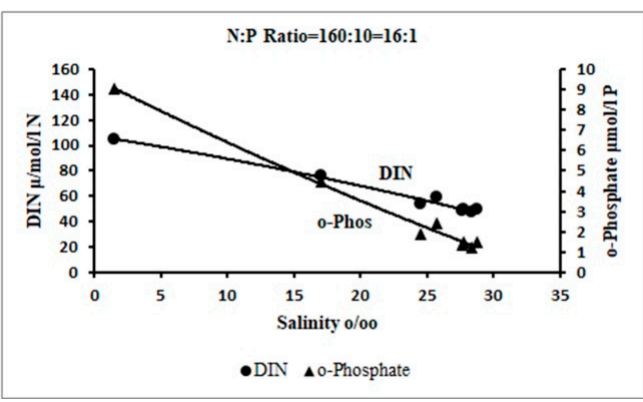

(c)

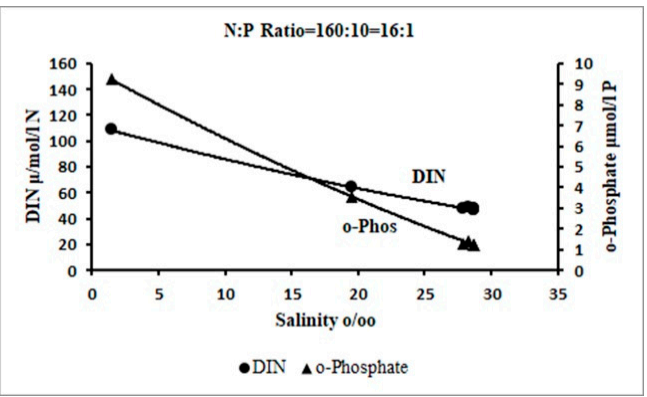

(e)

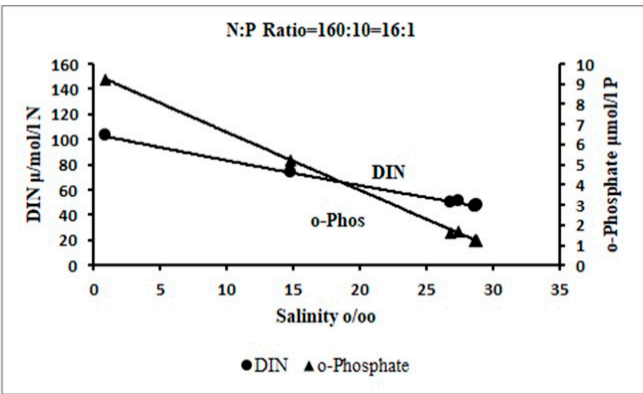

$(\mathrm{g})$

Figure 10. Overlay chart of mean salinity and nutrients (including DIN and o-phosphate) of representative vertical lines for the estuarine systems before and after the construction of the proposed sluice in Jiaojiang River estuary. Notes: In this figure, $\mu \mathrm{mol} / \mathrm{L} \mathrm{N}=[(\mathrm{mg} / \mathrm{L} \mathrm{N}) \times 1000] / 14, \mu \mathrm{mol} / \mathrm{L} \mathrm{P}[(\mathrm{mg} / \mathrm{L} \mathrm{P}) \times 1000] / 31$, where 14 and 31 are the relative atomic masses of $\mathrm{N}$ and $\mathrm{P}$, respectively. (a) Initial state of estuary and coastal water; (b) discharged with flow of $1500 \mathrm{~m}^{3} / \mathrm{s}$ during spring tide; (c) discharged with flow of $3000 \mathrm{~m}^{3} / \mathrm{s}$ during spring tide; (d) discharged with flow of $5000 \mathrm{~m}^{3} / \mathrm{s}$ during spring tide; (e) discharged with flow of $1500 \mathrm{~m}^{3} / \mathrm{s}$ during neap tide; (f) discharged with flow of $3000 \mathrm{~m}^{3} / \mathrm{s}$ during neap tide; (g) discharged with flow of $5000 \mathrm{~m}^{3} / \mathrm{s}$ during neap tide. 
In addition to the slow flow rate, the current recognized conditions for phytoplankton growth include suitable salinity and sufficient nutrients [35]. Studies on the Yangtze River estuary and adjacent estuaries showed that, under the influence of the diluted water tongue in summer, within the area with salinity value between $15 \%$ ond $25 \%$, the amount of phytoplankton could reach a yearly peak and the area was also a high-incidence area of red tide [36]. Therefore, the area with an average salinity of $15 \%$ o- $25 \%$ o under different operation schemes was counted, and the relationship between schemes and area is presented in Figure 11. The analysis was carried out in combination with the nutrient situation in the salinity area (Figure 10). The results showed that in the salinity area (15\%o-25\%o), when the water discharged at a small flow rate at spring tide, the estuary was under P limitation, which was the same as the initial state. In this situation, for phytoplankton that had adapted to the change of the salinity and nutrients in the estuary, the high nutrient concentration brought by the discharged water would allow them to grow in large quantities and may form an algal bloom. Conversely, when the estuarine sluice opened in other ways, the salinity zone was in the $\mathrm{N}$ and $\mathrm{P}$ limitation alternating zone. Therefore, to adapt to the changes in nutrient structure, phytoplankton need to pay more energy to regulate physiological activities thus resulting in the decrease of species diversity and interspecific competition, which may lead to the proliferation of harmful or potentially harmful species.

To sum up, when the estuarine sluice was in operation, a salinity area suitable for phytoplankton growth would be formed within the range of $8-14 \mathrm{~km}$ from the estuarine sluice $(15 \%$ o $<\mathrm{s}<25 \%$ o). In this area, there were not only abundant nutrients brought by water discharge, but also lower suspended sediment content and higher transparency than coastal areas. Therefore, some algae species with wide temperature, extensive salinity and strong adaptability, mainly Bacillariophyta, would rapidly reproduce and reach a peak and very likely, may form the red tide.

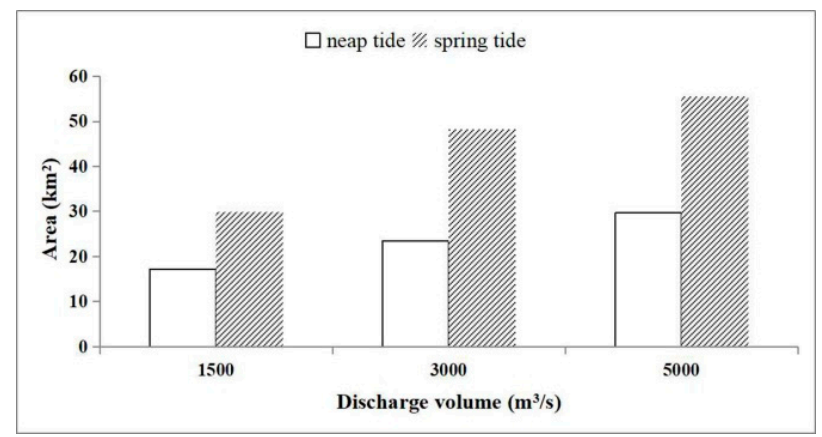

Figure 11. Salinity interval area suitable for phytoplankton growth under different scheduling schemes.

\section{Conclusions}

MIKE 21 water environment platform model was successfully applying to Jiaojiang River estuary, and simulations had provided reasonably good predictions in the region, and model values showed a good fit. The mathematical model could be used to simulate the influence of different operations on the water body after the construction of proposed estuarine sluice. The simulation results showed that the eutrophic freshwater on the sluice would change the concentration of salinity and nutrients under the sluice. The simulation results demonstrate that when the sluice was in operation, the area under the sluice would change from the saltwater area to an interaction zone of freshwater, brackish water and saltwater. Moreover, with the increase of salinity, the concentration of nutrients would decrease due to the dilution of seawater. The better relationship between nutrients and salinity (Figure 10) also showed that physical mixing played a vital role in nutrient decline.

The adverse factors caused by the discharging of estuarine sluice included sharp changes in salinity and changes in nutrients distribution. More important, the degree to which adverse factors affected the organisms varied with the scheduling schemes. First of all, the change of the salinity field would have an impact on the organisms in the aquaculture area. The minimum salinity in aquaculture areas under different sluice opening methods was higher than the tolerance threshold of organisms, 
indicating that the opening of sluice would not cause the death of mariculture organisms. However, a sharp fall in salinity value caused by the selection of large discharge would have a particularly negative impact on its growth (Figure 9). Second, for phytoplankton, the releasing of water may form a red tide explosion area under the estuarine sluice, and the area and quantity were firmly related to the scheduling schemes. The sequence from high to low is small flow at spring tide, large flow at spring tide, large flow at neap tide, small flow at neap tide (Figures 10 and 11). In conclusion, to reduce the stress on aquaculture organisms and the range of red tide, it is suggested that the proposed tide sluice at Jiaojiang River estuary should choose the mode of draining frequent with the small flow at neap tide as far as possible.

The appraisal of the long-term effects of the construction of sluice on estuarine ecosystem can provide a suggestion to carry out the ecological restoration measures for estuary and riparian zones. Above all, improving the water network circulation and the treatment standard of the sewage treatment plant is an indispensable implementation measure to recover the river water quality. In addition, ecological dredging of coastal tidal flat is the most promising restoration action in many polluted estuaries. It is also encouraged to use motor vessel to move back and forth to mix water quality when receiving the tide and increase the inflow of high-salinity tide before drainage.

Author Contributions: Conceptualization, X.W.; Methodology, X.W. and C.J.; Software, X.W., M.Z. and M.Y.; Validation, X.W., M.Z. and M.Y.; Formal Analysis, X.W.; Investigation, X.W.; Resources, C.J.; Data Curation, X.W.; Writing-Original Draft Preparation, X.W.; Writing-Review \& Editing, C.J. and T.Z.; Visualization, X.W.; Supervision, C.J. All authors have read and agreed to the published version of the manuscript.

Funding: This research received no external funding.

Acknowledgments: The authors would like to thank the Taizhou Water Conservancy Bureau and the Zhejiang Hohai Surveying and Mapping Institute for providing their monitoring data used in this study.

Conflicts of Interest: The authors declare no conflict of interest.

\section{References}

1. Ribeiro, C.; Couto, C.; Ribeiro, A.R.; Maia, A.S.; Santos, M.; Tiritan, M.E.; Pinto, E.; Almeida, A.A. Distribution and environmental assessment of trace elements contamination of water, sediments and flora from Douro River estuary, Portugal. Sci. Total Environ. 2018, 639, 1381-1393. [CrossRef]

2. Hughes, D.A.; Mallory, S.J.L. Including environmental flow requirements as part of real-time water resource management. River Res. Appl. 2008, 24, 852-861. [CrossRef]

3. Liu, W.-C.; Ke, M.-H.; Liu, H.-M. Response of Salt Transport and Residence Time to Geomorphologic Changes in an Estuarine System. Water 2020, 12, 1091. [CrossRef]

4. Wolanski, E.; Eliott, M. Estuarine Ecohydrology: An Introduction, 2nd ed.; Elsevier: Amsterdam, The Netherlands, 2015.

5. Jiang, C.L.; Yan, Y.X. Impact of water conservancy project on ecosystem and environment of the Yangtze River estuary. Resour. Environ. Yangtze Basin 2003, 12, 547-551. [CrossRef]

6. Senneville, S.; Schloss, I.R.; Drouin, S.S.O.; Bélanger, S.; Winkler, G.; Dumont, D.; Johnston, P.; St-Onge, I. Moderate effect of damming the Romaine River (Quebec, Canada) on coastal plankton dynamics. Estuar. Coast. Shelf Sci. 2018, 203, 29-43. [CrossRef]

7. Chai, C.; Yu, Z.; Shen, Z.; Song, X.; Cao, X.; Yao, Y. Nutrient characteristics in the Yangtze River Estuary and the adjacent East China Sea before and after impoundment of the Three Gorges Dam. Sci. Total Environ. 2009, 407, 4687-4695. [CrossRef]

8. Parida, A.K.; Das, A.B. Salt tolerance and salinity effects on plants: A review. Ecotoxicol. Environ. Saf. 2005, 60, 324-349. [CrossRef]

9. Cozzi, S.; Ibáñez, C.; Lazar, L.; Raimbault, P.; Giani, M. Flow Regime and Nutrient-Loading Trends from the Largest South European Watersheds: Implications for the Productivity of Mediterranean and Black Sea's Coastal Areas. Water 2018, 11, 1. [CrossRef]

10. Renjith, K.R.; Mary, J.M.; Kumar, C.S.R.; Manju, M.N.; Chandramohanakumar, N. Nutrient Distribution and Bioavailability in a Tropical Microtidal Estuary, Southwest India. J. Coast. Res. 2016, 322, 1445-1455. [CrossRef] 
11. Kamal, A.H.M.M.; Mair, G.C. Salinity tolerance in superior genotypes of tilapia, Oreochromis niloticus, Oreochromis mossambicus and their hybrids. Aquaculture 2005, 247, 189-201. [CrossRef]

12. Woo, N.Y.S.; Kelly, S.P. Effects of salinity and nutritional status on growth and metabolism of Spams sarba in a closed seawater system. Aquaculture 1995, 135, 229-238. [CrossRef]

13. Yin, K.D.; Harrison, P.; Goldblatt, R.H.; Beamish, R.J. Spring bloom in the central Strait of Georgia: Interactions of river discharge, winds and grazing. Mar. Ecol. Prog. 1996, 138, 255-263. [CrossRef]

14. Jiang, Y.J.; He, W.; Liu, W.X.; Qin, N.; Ouyang, H.L.; Wang, Q.M.; Kong, X.Z.; He, Q.S.; Yang, C.; Yang, B.; et al. The seasonal and spatial variations of phytoplankton community and their correlation with environmental factors in a large eutrophic Chinese lake (Lake Chaohu). Ecol. Indic. 2014, 40, 58-67. [CrossRef]

15. Desmit, X.; Thieu, V.; Billen, G.; Campuzano, F.; Dulière, V.; Garnier, J.; Lassaletta, L.; Ménesguen, A.; Neves, R.; Pinto, L.; et al. Reducing marine eutrophication may require a paradigmatic change. Sci. Total Environ. 2018, 635, 1444-1466. [CrossRef]

16. Hui, F.; Jun, H.H. Response of coastal marine eco-environment to river fluxes into the sea: A case study of the Huanghe (Yellow) River mouth and adjacent waters. Mar. Environ. Res. 2008, 65, 378-387. [CrossRef]

17. Adams, J.B.; Bate, G.C.; Harrison, T.D.; Huizinga, P.; Taljaard, S.; Van Niekerk, L.; Plumstead, E.E.; Whitfield, A.K.; Wooldridge, T.H. A method to assess the freshwater inflow requirements of estuaries and application to the Mtata estuary, South Africa. Estuaries 2002, 25, 1382-1393. [CrossRef]

18. Buzan, D.; Lee, W.; Culbertson, J.; Kuhn, N.; Robinson, L. Positive Relationship between Freshwater Inflow and Oyster Abundance in Galveston Bay, Texas. Estuaries Coasts 2008, 32, 206-212. [CrossRef]

19. Pelrson, W.L.; Nittim, R.; Chadwick, M.J.; Bishop, K.A.; Horton, P.R. Assessment of changes to saltwater/ freshwater habitat from reductions in flow to the Richmond River estuary, Australia. Water Sci. Technol. A J. Int. Assoc. Water Pollut. Res. 2001, 43, 89-97. [CrossRef]

20. Han, Z.C.; You, A.J.; Xu, Y.C.; Zhu, Y.S. Calculation methods of environmental and ecological water demand for macro-tidal estuary. J. Hydraul. Eng. 2006, 37, 395-402. [CrossRef]

21. Ying, C.Q.; Ling, L.J.; Chung, H.K.; Feng, Y.Z. Development of a relative risk model for evaluating ecological risk of water environment in the Haihe River Basin estuary area. Sci. Total Environ. 2012, 420, 79-89. [CrossRef]

22. Liang, D.; Wang, X.; Bockelmann-Evans, B.N.; Falconer, R.A. Study on nutrient distribution and interaction with sediments in a macro-tidal estuary. Adv. Water Resour. 2013, 52, 207-220. [CrossRef]

23. Luo, H.; Huang, G.; Wu, X.; Peng, J.; Fu, X.; Luo, L. Ecological engineering analysis and eco-hydrodynamic simulation of tidal rivers in Shenzhen City of China. Ecol. Eng. 2009, 35, 1129-1137. [CrossRef]

24. Le, T.V.H.; Nguyen, H.N.; Wolanski, E.; Tran, T.C.; Haruyama, S. The combined impact on the flooding in Vietnam's Mekong River delta of local man-made structures, sea level rise, and dams upstream in the river catchment. Estuar. Coast. Shelf Sci. 2007, 71, 110-116. [CrossRef]

25. Jun, Z.C.; Qinag, L.; Feng, Y.; Long, H.W. Reduction of waste water in Erhai Lake based on MIKE21 hydrodynamic and water quality model. Sci. World J. 2013, 2013, 958506. [CrossRef]

26. Paliwal, R.; Patra, R.R. Applicability of MIKE 21 to assess temporal and spatial variation in water quality of an estuary under the impact of effluent from an industrial estate. Water Sci. Technol. 2011, 63, 1932-1943. [CrossRef]

27. Warren, I.R.; Bach, H.K. MIKE 21: A modelling system for estuaries, coastal waters and seas. Environ. Softw. 1992, 7, 229-240. [CrossRef]

28. Liao, Y.B.; Shou, L.; Jiang, Z.B.; Gao, A.G.; Zeng, J.N.; Chen, Q.Z.; Yan, X. Benthic macrofaunal communities along an estuarine gradient in the Jiaojiang River estuary, China. Aquat. Ecosyst. Health Manag. 2016, 19, 314-325. [CrossRef]

29. Qian, J.; Chen, L.H.; Feng, W.H.; Xiang, Y.; Wang, Z.F. Analysis of reclamation intensity and environmental impact in Jiaojiang estuary. Ocean Dev. Manag. 2018, 35, 62-66.

30. Gou, H.; Luo, F.; Li, R.; Dong, X.; Zhang, Y. Modeling Study on the Hydrodynamic Environmental Impact Caused by the Sea for Regional Construction near the Yanwo Island in Zhoushan, China. Water 2019, 11, 1674. [CrossRef]

31. Marshall, H.G.; Lacouture, R.V.; Buchanan, C.; Johnson, J.M. Phytoplankton assemblages associated with water quality and salinity regions in Chesapeake Bay, USA. Estuar. Coast. Shelf Sci. 2006, 69, 10-18. [CrossRef]

32. Hodgkiss, I.J.; Ho, K.C. Are changes in N:P ratios in coastal waters the key to increased red tide blooms? Hydrobiologia 1997, 352, 141-147. [CrossRef] 
33. Neill, M. A method to determine which nutrient is limiting for plant growth in estuarine waters-at any salinity. Mar. Pollut. Bull. 2005, 50, 945-955. [CrossRef]

34. Redfield, A.C. On The Proportions of Organic Derivations in Sea Water and Their Relation to The Composition of Plankton. In James Johnstone Memorial Volume; University of Liverpool: Liverpool, UK, 1934; pp. 176-192.

35. Dong, L.; Lin, L.; Tang, X.; Huang, Z.; Zhao, L.; Wu, M.; Li, R. Distribution Characteristics and Spatial Differences of Phosphorus in the Main Stream of the Urban River Stretches of the Middle and Lower Reaches of the Yangtze River. Water 2020, 12, 910. [CrossRef]

36. Chen, C.; Zhu, J.; Beardsley, R.C.; Franks, P.J.S. Physical-biological sources for dense algal blooms near the Changiiang River. Geophys. Res. Lett. 2003, 30. [CrossRef]

(C) 2020 by the authors. Licensee MDPI, Basel, Switzerland. This article is an open access article distributed under the terms and conditions of the Creative Commons Attribution (CC BY) license (http://creativecommons.org/licenses/by/4.0/). 